\title{
KONFLIK AMERIKA SERIKAT DAN IRAN PASCA-TERBUNUHNYA KEPALA KORPS QUDS GARDA REVOLUSI IRAN MAYOR JENDERAL QASEM SOLEIMANI PADA 2020
}

\author{
Devih Desdian Dwi Hendra \\ devihdesdian.dh93@gmail.com
}

Tom Finaldin

tomfinaldin@unfari.ac.id

\author{
Fakultas Ilmu Sosial dan Ilmu Politik \\ Universitas Al-Ghifari
}

\begin{abstract}
Devih Desdian Dwi Hendra, C1A170167, Conflict of the United States and Iran Post-Killing of the Head of the Quds. Corps of the Iranian Revolutionary Guard Major General Qasem Soleimani In 2020, Faculty of Social and Political Sciences International Relations Studies Program Al-Ghifari University, 2020, Advisor Tom Finaldin, A.Md., SIP, M.Sc..The purpose of this study is to examine the extent to which the attacks carried out by the United States againts Iran on the orders of President Donald Trump, which killed the head of the Iranian Revolutionary Guard Quds Corps Major General Qasem Soleimani were actually motivated by US interests alone. Even if the reason given is to stop the war and not to start a war and save from a major attack on the citizens of the United States in the Middle East, the US therefore prevents it by attacking first. The results of this study indicate that in this conflict case, the United States has violated international law. There are two things that are volated by the United States. Firts, it violates international law, commits assassinations of other countries in a state of non-war and secondly, violates agreements between Iraq and America itself, which include no violation of sovereignty. Despite the loss of an influential military leader, the death of Mayor General Qasem Soleimani could benefit Iran in the short term. Iran has the opportunity to show its ability to unite in times of crisis, unite the political elite that
\end{abstract}


has been divided. Thus the realization of national interests for the future in the aspirations of its people as a sovereign nation.

Keywords : Conflict, United States, Iran 


\section{Pendahuluan}

Perkiraan peperangan besar yang dikhawatirkan akan menyeret dunia ke ambang kehancuran menjadi menu pembuka 2020. Hal itu berawal dari perintah Presiden Amerika Serikat (AS), Donald Trump untuk menyerang dan menewaskan Kepala Korps Quds Garda Revolusi Iran Mayor Jenderal Qasem Soleimani setelah dihantam rudal oleh pesawat nirawak Amerika Serikat (AS) di Bandara Internasional Baghdad, Irak, pada Jumat (3/1/2020) lalu. ${ }^{1}$ Peristiwa itu memicu kemarahan besar, baik dari warga maupun pemerintah Iran. Sebagai balasan, Iran menyerang markas militer Amerika Serikat (AS) di Irak pada Rabu (8/1/2020) dini hari. ${ }^{2}$

Kawasan Timur Tengah selalu dibarengi oleh pertumpahan darah. Konflik Israel-Palestina, perang sipil di Yaman dan Suriah, sarang terorisme di Irak dan Suriah adalah beberapa contohnya. Kini perseteruan Amerika Serikat dan Iran juga menjadi bom waktu bagi kawasan tersebut dan juga seluruh dunia. $^{3}$

Keputusan Donald Trump supaya Amerika Serikat (AS) menarik diri

\footnotetext{
${ }^{1}$ CNN Indonesia, "Konflik AS-Iran, Ancaman Petaka dari Timur Tengah" 09 (Januari) 2020,

http://m.cnnindonesia.com/internasional/202 00109104223-120-463756/konflik-as-iranancaman-petaka-dari-timur-tengah [02/02/2020]

${ }^{2}$ Ahmad Naufal Dzulfaroh, "Merunut Akar Konflik Iran-Amerika Serikat, Sejak Kapan Perseturuan Dimulai?" 10 (Januari) 2020, http://www.kompas.com/tren/read/2020/01/1 0/103042265/merunut-akar-konflik-iranamerika-serikat-sejak-kapan-perseteruandimuai [02/02/2020]

${ }^{3} \mathrm{CNN}$ Indonesia Loc. cit.
}

dari perjanjian nuklir Joint Comprehensive Plan of Action (JCPOA) 2015 yang ditandatangani pendahulunya, Barack Obama, dua tahun lalu memicu amarah Iran. Alasannya adalah Donald Trump menuduh Iran tetap melanjutkan program peluru kendali dan terlibat dalam sejumlah konflik di Timur Tengah.

Hal itu pun menjadi landasan Amerika Serikat (AS) menjatuhkan sanksi baru bagi Iran. Ketegangan berimbas ke wilayah Teluk Persia yang menjadi urat nadi pengiriman minyak dunia. Serangan yang menewaskan Soleimani bisa menjadi pembuka persoalan baru di Timur Tengah. Hal itu disebabkan dia dianggap sebagai salah satu perwira militer yang cukup berpengaruh di Timur Tengah. Dia sudah malang melintang membentuk dan membina hubungan dengan sejumlah milisi Syiah di daerah tersebut. ${ }^{4}$

Pembunuhan Komandan Pasukan Quds Jenderal Qassem Soleimani merupakan eskalasi dramatis dalam konflik antara Amerika Serikat dan Iran. Pembunuhan yang diinisiasi Presiden Amerika Serikat Donald Trump tersebut konsekuwensinya bisa sangat besar. Trump mengatakan Amerika Serikat membunuh komandan militer Iran itu untuk menghentikan perang dan bukan untuk memulai perang.

Jenderal Soleimani sambung dia, dibenci dan ditakuti di negaranya sendiri dan seharusnya sudah dibunuh bertahun-tahun yang lalu. ${ }^{5}$

\footnotetext{
${ }^{4}$ CNN Indonesia Loc. cit.

${ }^{5}$ Haufan Hasyim Salengke, "Kenapa AS Akhirnya Membunuh Jenderal Top Iran Qaseem Soleimani?" 049 (Januari) 2020, https://mediaindonesia.com/read/detail/2812
} 
Kekuasaan teror Soleimani telah berakhir ujar Trump setelah serangan pesawat nirawak Amerika Serikat di Nandara Baghdad, Irak, Jum'at (3/1/2020), yang merenggut nyawa komandan Pengawal Revolusi Iran tersebut. Trump berkilah rezim yang ia pimpin tidak sedang mencari perang atau hendak melakukan perubahan kepemimpinan di Iran. Sebaliknya, Trump mengaku ingin mencegah Jenderal Soleimani yang dia sebut sebagai 'monster sakit' dan 'teroris nomor satu di dunia' ${ }^{6}$

Amerika Serikat mengatakan kepada Perserikatan Bangsa-Bangsa (PBB) bahwa pembunuhan Komandan Iran Qasem Soleimani pekan lalu adalah bentuk pertahanan diri dan berjanji untuk mengambil tindakan tambahan seperlunya di Timur Tengah untuk melindungi personil dan Kepentingan Amerika Serikat. ${ }^{7}$

Presiden Amerika Serikat, Donald Trump, menyatakan mempunyai alasan untuk memerintahkan membunuh Soleimani. Trump berdalih Soleimani merencanakan serangan besar terhadap warga Amerika Serikat di Timur Tengah, maka dari itu dia mencegahnya dengan menyerang terlebih dahulu. ${ }^{8}$

Presiden Amerika Serikat, Donald Trump kembali bersuara terkait tewasnya Mayor Jenderal Qasem

89-kenapa-as-akhirnya-membunuh-jenderaltop-iran-qaseem-soleimani [20/02/2020]

${ }^{6}$ Media Indonesia (ed). Ibid.

${ }^{7}$ Benedikta Miranti Tri Verdiana "Kepada

PBB, AS Sebut Pembunuhan Qasem

Soleimani Jadi Cara Untuk Bela Diri” 09

(Januari) 2020,

https://m.liputan6.com/global/read/4151867/

kepada-pbb-as-sebut-pembunuhan-qasem-

soleimani-jadi-cara-untuk-bela-diri

[20/02/2020]

${ }^{8}$ CNN Indonesia, Loc. cit.
Soleimani. Ia berusaha menjelaskan bahwa Soleimani memberikan ancaman rill pada Amerika Serikat. Dilansir VOA Indonesia, Jum'at (10/1/2020). Trump menyatakan mendiang Mayor Jenderal Qasem Soleimani sedang merencanakan akan meledakan kedutaaan besar Amerika Serikat di Baghdad, Irak, sebelum ia terbunuh dalam serangan drone Amerika Serikat. ${ }^{9}$

Keputusan untuk membunuh Mayor Jenderal ini merupakan sebuah keputusan yang sangat sulit. Pasalnya, kematiannya akan menimbulkan konflik besar. Benar, saat ini Iran menyiapkan strategi balas dendam. Selain itu, Amerika Serikat mendapat kecaman dari beberapa negara seperti Perancis dan Rusia. $^{10}$

Mayor Jenderal Qasem Soleimani merupakan perwira militer senior Iran dalam Pasukan Pengawal Revolusi Islam The Islamic Revolutionary Guard Corps (IRGC), cabang militer terbesar di Militer Iran. Qassem merupakan Panglima Pasukan Quds atau pasukan khusus (cabang) dari pasukan bermotto "Bersiap melawan mereka dengan kekuatan yang kau bisa" ini.

Amerika Serikat mencurigai tiga agenda yang dilakukan oleh Pasukan Quds. Pertama, Pasukan Quds disebut sebagai instrumen utama rezim Iran untuk memberikan dukungan mematikan kepada

\footnotetext{
${ }^{9}$ Liputan6, Loc. cit.

${ }^{10}$ Neno Anderias Salukh, "Mengapa AS

Membunuh Jenderal Top Iran (Qassem

Soleimani)? 04 (Januari) 2020,

https://www.kompasiana.com/neno1069/5e1 0204a097f360cac3a83b2/mengapa-asmembunuh-jenderal-top-iran-qassemsoleimani [20/02/2020]
} 
kelompok-kelompok Taliban untuk mendukung kegiatan anti-Amerika Serikat dan anti-Koalisi di Afghanistan.

Kedua, Pasukan Quds memiliki sejarah panjang dalam mendukung kegiatan militer, paramiliter, dan teroris Hizbullah dengan memberikan bimbingan, pendanaan, senjata, intelijen, dan dukungan logistik.

Ketiga, Pasukan Quds memberikan dukungan mematikan dalam bentuk senjata, pelatihan, pendanaan, dan panduan untuk memilih kelompokkelompok militan Syiah Irak seperti Negara Islam Irak dan Suriah (ISIS) untuk membunuh koalisi dan pasukan Irak serta warga sipil Irak yang tidak bersalah.

Kecurigaan inilah yang terus membuat Amerika Serikat mengintai keberadaan Pasukan Quds. Rupanya, kekuatan pasukan khusus di bawah kepemimpinan Qassem Soleimani tidak dapat dipandang sebelah mata. Intervensi militer dengan penanaman ideologi dan strategi diplomasi yang keras kepala identik dengan kepemimpinan Qassem Soleimani. Selain itu, ia memiliki pengaruh politik dan militer di Irak melalui partai politik Syiah dan Kurdi, yang memberontak terhadap Saddam Hussein pada Pemberontakan Irak $1991{ }^{11}$

Kematian Soleimani dianggap sebagai pukulan telak bagi Iran. Dia yang membentuk banyak milisi Syiah di Timur Tengah. Jika dia tidak turun tangan dengan membentuk milisi, kemungkinan Bashar Al-Assad sudah tidak berkuasa lagi akibat pemberontakan,

${ }^{11}$ Kompasiana (ed). Ibid. menganggap sampai saat ini Iran belum mempunyai pengganti sosok Soleimani. Hal itu disebabkan prestasinya dianggap belum ada yang menandingi. Sikap Trump yang langsung menghabisi Soleimani sangat bertolak belakang dengan kedua Presiden Amerika Serikat (AS) Obama dan George W. Bush. Mereka juga sempat terpikir melakukan hal itu tetapi risikonya terlampau tinggi. ${ }^{12}$

Merunut ke belakang, bahwa perseteruan Amerika Serikat (AS)Iran ini dimulai Pertama, kita harus melihat bahwa hubungan Amerika Serikat (AS)-Iran itu tidak pernah harmonis sejak Revolusi Islam Iran 1979. Sebelum itu, Amerika Serikat (AS) memiliki hubungan yang sangat akrab dengan Iran dan selalu mendukung Shah Mohammed Reza Pahlevi. Bahkan, saat embargo minyak besar-besaran yang dilakukan oleh negara-negara di Timur Tengah karena pendudukan Israel, Iran menjadi pemasok minyak tetap Amerika Serikat (AS). Saat revolusi, mahasiswa Iran menduduki Kedutaan Besar Amerika Serikat (AS) di Teheran selama 444 hari. Dalam Ilmu Hubungan Internasional, kedutaan dalam suatu negara harus dianggap sebagai perpanjangan wilayah dari negara tersebut. Artinya, apa yang dilakukan mahasiswa Iran itu berarti sama dengan menduduki negara.

Hal itu diperburuk dengan mencuatnya skandal Iranian Gate, ketika Presiden Amerika Serikat (AS) Ronald Reagen diketahui menjual senjata kepada Iran tanpa persetujuan senat. Penjualan senjata

\footnotetext{
${ }^{12}$ CNN Indonesia, Loc. cit.
} 
tersebut dilakukan melalui barter dengan tawanan Amerika Serikat (AS) pada 1980. Skandal tersebut membuat Amerika Serikat (AS) sangat malu karena melanggar undang-undang sendiri. ${ }^{13}$

Dendam-dendam masa lalu itu menjadi akar penyebab panasnya hubungan Amerika Serikat (AS)-Iran hingga saat ini. Rasa dendam itu kemudian dilampiaskan dengan embargo, Amerika Serikat (AS) dan negara-negara sahabatnya tidak akan mengambil minyak dari Iran. Selain embargo, Amerika Serikat (AS) juga menuduh Iran tengah mengembangkan senjata nuklir. Adapun menurut Iran, pengembangan nuklir adalah untuk kepentingan kemanusiaan, penerangan, dan kedokteran. Akan tetapi, Amerika Serikat (AS) tidak percaya sampai Iran dikenakan sanksi. Dalam perjalanannya, hubungan Amerika Serikat (AS) dan Iran diwarnai pasang surut. Berikut catatan hubungan kedua negara. ${ }^{14}$

Pada 1953 Central Intelligence Agency (CIA) membantu pelengseran Perdana Menteri Iran kala itu, Mohammed Mossadegh, dan memulihkan kekuasaan Shah Mohammed Reza Pahlevi.

Pada 1957 Amerika Serikat (AS)Iran menandatangani perjanjian kerjasama nuklir sipil.

Pada 1967 Amerika Serikat (AS) memberi Iran reaktor nuklir dan

\footnotetext{
${ }^{13}$ Ahmad Naufal Dzulfaroh, "Merunut Akar Konflik Iran-Amerika Serikat, Sejak Kapan Perseteruan Dimulai” 10 (Januari) 2020 , https://www.kompas.com/tren/read/2020/01/ 10/103042265/merunut-akar-konflik-iranamerika-serikat-sejak-kapan-perseteruandimulai $[06 / 03 / 2020]$

${ }^{14}$ Kompas (ed), Ibid.
}

senjata uranium. Pada 1968 Iran menandatangani Perjanjian NonProliferasi Nuklir yang mengizinkannya memiliki program nuklir sipil sebagai imbalan atas komitmennya untuk tidak membeli senjata nuklir.

Pada 1979 Revolusi Islam Iran memaksa Shah Reza Pahlevi yang didukung Amerika Serikat (AS) untuk melarikan diri. Setelah Ayatollah Ruhollah Khomeini kembali dari pengasingan dan menjadi pemimpin tertinggi Iran, ratusan orang menduduki Kedutaan Besar Amerika Serikat (AS) di Ibukota Teheran dan menyandera staffnya. ${ }^{15}$

Pada 1980 Amerika Serikat (AS) memutuskan hubungan diplomatik dengan Iran, menyita aset Iran dan melarang hubungan dagang dengan Iran Disamping itu, terjadi kegagalan misi penyelamatan sandera yang dipesan oleh Presiden Jimmy Carter. Pada 1980 Iran melepaskan 52 sandera Amerika Serikat (AS) beberapa menit setelah Carter turun dan Ronald Reagan dilantik sebagai presiden Amerika Serikat (AS).

Pada 1984 Amerika Serikat (AS) memasukkan Iran ke dalam daftar negara pendukung terorisme. Pada 1986 Reagan mengungkap perjanjian senjata rahasia dengan Teheran yang melanggar embargo senjata Amerika Serikat.

Pada 1988 Kapal perang Amerika Serikat (AS) Vinecennes salah menembak pesawat penumpang yang terbang di atas Teluk Arab dan 290 penumpangnya meninggal.

Pada 2002 Presiden George W Bush menyatakan Iran, Irak dan Korea

\footnotetext{
${ }^{15}$ Kompas (ed), Ibid.
} 
Utara sebagai poros kejahatan. Para pejabat Amerika Serikat (AS) menuduh Teheran mengoperasikan program senjata nuklir rahasia. ${ }^{16}$

Pada 2006 Washington mengatakan bersedia untuk bergabung dengan perundingan nuklir multilateral dengan Iran jika negara itu menangguhkan program nuklir.

Pada 2008 Bush untuk pertama kalinya mengirim seorang pejabat untuk mengambil bagian secara langsung dalam negosiasi nuklir dengan Iran di Geneva.

Pada 2009 Presiden Barack Obama memberitahu pemimpin Iran bahwa bersedia membantunya jika Iran mau melepas kepalan tangan mereka.

Pada 2009 Inggris Perancis dan Amerika Serikat (AS) mengumumkan bahwa Iran tengah membangun situs pengayaan uranium rahasia di Fordow, Iran.

Pada 2012 Hukum Amerika Serikat (AS) memberi Barack Obama wewenang untuk menjatuhkan sanksi kepada bank asing jika mereka gagal mengurangi impor minyak Iran secara signifikan. Penjualan minyak Iran pun anjlok dan memicu kemerosotan ekonomi.

Pada 2013 Hassan Rouhani terpilih sebagai presiden Iran dan memiliki tujuan untuk meningkatkan hubungan Iran dengan dunia.

Pada 2013 September, Obama dan Rouhani berbicara melalui telepon, kontak tertinggi antara dua negara dalam tiga dekade terakhir.

Pada 2013 November, Iran dan enam negara besar menandatangani kesepakatan nuklir dalam fakta Joint Comprehensive Plan of Action (JCPOA). Iran setuju untuk

\footnotetext{
${ }^{16}$ Kompas (ed), Ibid.
}

membatasi program nuklirnya dengan imbalan pencabutan sanksi. ${ }^{17}$ Pada 2016 Iran melepas sepuluh pelaut Amerika Serikat (AS) di perairan teritorial Iran; Amerika Serikat (AS) dan Iran melakukan pertukaran tahanan.

Pada 2018 Presiden Donald Trump menarik diri dari kesepakatan nuklir dan menerapkan kembali sanksi ekonomi kepada Iran.

Pada April 2019 Amerika Serikat (AS) memasukkan Korps Pengawal Revolusi Iran ke dalam daftar organisasi teroris. Pada 2019 Iran meningkatkan produksi uranium dan membatalkan komitemennya pada perjanjian nuklir.

Pada 2019 Juni Iran menembak jatuh pesawat tak berawak Amerika Serikat (AS) yang disebut sedang berada di wilayah udara Iran; Iran merebut kapal tanker minyak Inggris. Pada 2019 September, perusahaan minyak Arab Saudi, Aramco diserang oleh drone dan rudal yang diyakini berasal dari Iran. Teheran membantah terlibat dalam serangan itu.

Pada 2019 Desember, terjadi serangan terhadap pangkalan militer Amerika Serikat di Irak yang menewaskan seorang warga Amerika Serikat (AS). Amerika Serikat (AS) menyalahkan sekelompok milisi yang didukung Iran dan melakukan aksi balasan dengan menembak pangkalan-pangkalan militer Iran.

Pada 2019 Milisi yang didukung Iran melakukan aksi protes di luas Kedutaan Besar Amerika Serikat (AS) di Baghdad dan menyerbu pos keamanan. Pada 2020 Januari, Jenderal top Iran Qasem Soleimani

\footnotetext{
${ }^{17}$ Kompas, (ed), Ibid.
} 
meninggal dalam serangan udara Amerika Serikat (AS) yang dilakukan atas arahan Donald Trump. ${ }^{18}$

Pembunuhan Jenderal Qasem Soleimani oleh Amerika Serikat (AS) dan serangan pembalasan Iran dengan rudal ke pangkalan Amerika Serikat (AS) semakin meningkatkan kekhawatiran akan terjadinya perang yang berdampak luas. Hal ini bisa dilihat dari pembalasan yang dilakukan Iran dengan mengebom pangkalan militer Amerika Serikat (AS) di Irak pada Rabu (8/1/2020) dini hari.

Berkaitan dengan pasang surutnya hubungan Amerika Serikat dan Iran ditambah dengan pembunuhan Qasem Soleimani, konflik di Timur Tengah semakin memanas yang bisa menimbulkan perang terbuka dalam waktu yang tidak ditentukan. Hal ini akan mempengaruhi situasi politik antara Amerika Serikat dan Iran, Timur Tengah, bahkan dunia. Kerusakan pun akan menjadi tak terhindarkan bagi mereka yang terlibat langsung maupun tidak langsung. Oleh sebab itu, peneliti merasa tertarik untuk melakukan penelitian dengan judul Konflik Amerika Serikat dan Iran PascaTerbunuhnya Kepala Korps Quds Garda Revolusi Iran Mayor Jenderal Qasem Soleimani pada 2020.

\section{Kerangka Dasar Teori dan Konsep}

\section{Konsep Kepentingan Nasional}

Konsep kepentingan nasional telah menjadi sentral dalam studi Hubungan Internasional (HI) untuk waktu yang sangat lama (bahkan sejak kelahiran studi Hubungan

${ }^{18}$ Kompas (ed), Ibid.
Internasional sendiri) dan tetap menjadi fokus perhatian para penstudi Hubungan Internasional (HI) hingga saat ini.

Kepentingan nasional merupakan perangkat eksplanatori kunci (key explanatory tool) dalam memahami hubungan internasional, khususnya dalam analisis tentang diplomasi dan politik luar negeri. Hampir tidak ada analisis tentang politik luar negeri dan diplomasi suatu negara yang tidak menyinggung tentang faktor kepentingan nasional tersebut.

Menurut Theodore Couloumbis dan James Wolfe menyatakan bahwa: "Kepentingan nasional masih menjadi konsep yang sangat penting dalam setiap upaya mendeskripsikan, menjelaskan, memprediksikan atau membuat preskripsi tentang perilaku internasional". ${ }^{19}$ Adapun menurut Charles Beard bahwa:

"Kepentingan nasional adalah alasan negara (raison d'etat) di belakang tujuan-tujuan dan ambisi-ambisinya menjalankan hubungan internasional", 20

Pada intinya, banyak ilmuwan menggunakan gagasan atau konsep kepentingan nasional untuk menggambarkan alasan (reasoning), motivasi, atau justufikasi utama yang mendasari perilaku suatu negara dalam lingkungan global.

Kemudian Hans Morgenthau seorang pakar yang dikenal sebagai pelopor realisme dalam studi Hubungan Internasional (HI) menyamakan bahwa: "kepentingan nasional

\footnotetext{
${ }^{19}$ Umar Suryadi Bakry, Dasar-Dasar Hubungan Internasional, Depok, (2017), hlm. 58 .

${ }^{20}$ Umar Suryadi Bakry, Dasar-Dasar Hubungan Internasional, Depok, (2017), hlm. 58 .
} 
dengan power". ${ }^{21}$ yang ingin dikejar oleh suatu negara dalam hubungan internasional. Pemikiran Morgenthau ini didasarkan pada premis bahwa strategi diplomasi harus didasarkan pada kepentingan nasional, bukan pada alasan-alasan moral, legal dan ideologi yang dianggapnya utopis dan bahkan berbahaya.

"Ia menegaskan bahwa kepentingan nasional setiap negara dalam hubungan internasional adalah mengejar power. Morgenthau sendiri mendefinisikan power sebagai apa saja yang menjadikan dan mempertahankan kendali suatu negara terhadap negara lain". ${ }^{2}$

Lebih lanjut Morgenthau membagi kepentingan nasional ke dalam dua tingkat, yaitu:

1. Kepentingan Nasional Primer (vital)

Kepentingan nasional primer menyangkut perlindungan identitas fisik, politik, dan budaya, serta keamanan dan kelangsungan hidup dari suatu bangsa. Tidak ada kompromi dalam mewujudkan kepentingan nasional primer ini, bahkan suatu negara tidak raguragu berperang untuk hal itu.

2. Kepentingan Nasional Sekunder Kepentingan nasional sekunder adalah segala kepentingan dari suatu negara yang masih dapat dikompromikan atau diupayakan melalui dengan negara lain.

\footnotetext{
${ }^{21}$ Umar Suryadi Bakry, Dasar-Dasar Hubungan Internasional, Depok, (2017), hlm. 59.

${ }^{22}$ Umar Suryadi Bakry, Dasar-Dasar Hubungan Internasional, Depok, (2017), hlm. 59.
}

\section{Konsep Politik dan Kekerasan}

Politik bisa diartikan sebagai bermacam-macam kegiatan dalam suatu sistem politik (atau negara) yang menyangkut proses menentukan tujuan-tujuan dari sistem itu dan melaksanakan tujuantujuan itu. Untuk melaksanakan tujuan itu, ditentukan kebijaksanaan umum. Untuk melaksanakan kebijksanaan umum, perlu memiliki kekuasaan (power) dan kewenangan (authority). Politik, selalu menyangkut tujuan-tujuan dari seluruh masyarakat (public goods), dan bukan tujuan pribadi seseorang (private goals). ${ }^{23}$

Politik, dalam hal ini tidak bisa dipahami bahwa sebuah kegiatan pribadi saja. Karena pada dasarnya siapapun berhak untuk melakukan kegiatan politik.

Semua warga negara mempunyai hak yang sama dalam berpolitik. Karena dalam berpolitik tidak ada pembedaan antar warga negara. Dan politik hanya akan disebut sebagai kegiatan politik, dan bukan persengkokolan, cari kuasa atau main intrik, manakala ada keterbukaan. ${ }^{24}$ Sedangkan dalam kamus besar bahasa Indonesia, dijelaskan arti dari politik meliputi:

1. Pengetahuan mengenai ketatanegaraan, atau kenegaraan.

2. Segala urusan dan tindakan (kebijaksaan / siasat) mengenai pemerintahan negara / terhadap orang lain.

\footnotetext{
${ }^{23}$ Miriam Budiardjo (ed), Ibid.

${ }^{24}$ Emmanuel Subangun, Politik Anti Kekerasan Paska Pemilu '99', Pustaka Pelajar, Pustaka Pelajar, Yogyakarta, (1999), hlm.12.
} 
3. Cara bertidak (dalam menghadapi /menangani suatu masalah) kebijaksanaan. ${ }^{25}$

Rumlan Surbakti mendefinisikan politik sebagai:

1. Usaha-usaha yang ditempuh warga negara untuk membicarakan dan mewujudkan kebaikan bersama.

2. Segala hal yang berkaitan dengan penyelenggaraan negara dan pemerintah.

3. Segala kegiatan yang diarahkan untuk mencari dan mempertahankan kekuasaan dan masyarakat.

4. Kegiatan yang berkaitan dengan perumusan dan pelaksanaan kebijakan umum.

5. Dalam rangka mencari dan atau mempertahankan sumber-sumber yang dianggap penting. ${ }^{26}$

Dari definisi tersebut diatas, dapat diambil kesimpulan yang dimaksud dengan kekerasan politik adalah kekerasan yang dilakukan baik individu, (masyarakat sipil) maupun oleh negara, yang digerakkan oleh isu-isu yang bersifat politik terutama yang terkait dengan perjuangan mendapatkan kekuasaan di dalam organisasi politik. ${ }^{27}$ Sedangkan

Ted Robbert Gurr merumuskan bahwa kekerasan poltik adalah

"Sebagai bentuk dari semua tindakan kekerasan kolektif dalam suatu komunitas politik terhadap rezim politik, aktor politik, kelompok-

\footnotetext{
${ }^{25}$ Pusat Pembinaan dan Pengembangan Bahasa, Kamus Besar Bahasa Indonesia, Jakarta, Balai Pustaka, Edisi II, Cet.III, 1994. hlm.780.

${ }^{26}$ Ramlan Surbakti, Op.Cit., hlm.2.

${ }^{27}$ James Rule dalam Ariel Haryanto, Kekerasan Politik dalam Perlawanan dalam Kepatuhan, Mizan, 2000, hlm.211.
}

kelompok politik yang bersaing. Konsep itu menggambarkan serangkaian kejadian yang ciri pokoknya adalah penggunaan tindakan kekerasan yang termasuk dalam pengertian konsep itu adalah revolusi, perang geriliya, kudeta dan kerusuhan". 28

Dalam hal ini, konsep kekerasan politik menurut Gurr adalah semua bentuk peristiwa yang mempunyai unsur penggunaan atau ancaman penggunaan kekerasan yang dilakukan oleh aktor, atau kelompok aktor, yang menentang penguasa negara. Kekerasan politik, merupakan dari menurunnya respon struktur sosial, kepercayaan, norma, atau ketiganya terhadap perubahan obyektif. $^{29}$

\section{Metode Penelitian}

Jenis Penelitian yang digunakan adalah penelitian deskriptif analisis. Dimana peneliti menganalisis Konflik Amerika Serikat Dan Iran Pasca-Terbunuhnya Kepala Korps Quds Garda Revolusi Iran Mayor Jenderal Qasem Soleimani Pada 2020. Jenis data yang digunakan dalam penelitian ini adalah data sekunder, yaitu data yang diperoleh dari penelaahan studi kepustakaan dan hasil browsing data melalui jaringan internet. Teknik pengumpulan data yang digunakan dalam penelitian ini adalah telaah pustaka. Teknik analisis yang

\footnotetext{
${ }^{28}$ Ted Robert Gurr "Deprivasi relative dan Kekerasan”, dalam Thomas Santoso, Ibid, hlm.64.

${ }^{29}$ Ibid, hlm. 85 .
} 
digunakan teknik analisis data kualitatif yaitu peneliti menganalisis data sekunder yang kemudian menggunakan teori dan konsep untuk menjelaskan suatu fenomena atau kejadian yang sedang diteliti oleh peneliti yaitu Konflik Amerika Serikat Dan Iran Pasca-Terbunuhnya Kepala Korps Quds Garda Revolusi Iran Mayor Jenderal Qasem Soleimani Pada 2020.

\section{Pembahasan}

\section{Alasan AS Membunuh Qasem Soleimani}

\subsection{Demi Menghentikan Perang}

Pembunuhan Komandan

Pasukan Quds Jenderal Qassem

Soleimani merupakan eskalasi dramatis dalam konflik antara Amerika Serikat dan Iran. Pembunuhan yang diinisiasi Presiden Amerika Serikat Donald Trump konsekuensinya bisa sangat besar. Trump mengatakan AS membunuh komandan militer Iran itu untuk menghentikan perang dan bukan untuk memulai perang. Jenderal Soleimani, sambung dia, dibenci dan ditakuti di negaranya sendiri dan seharusnya sudah dibunuh bertahuntahun yang lalu.

Menurut pakar Hubungan Internasional (HI), James Dougherty dan Robert Pflaltzgraff konflik ialah: "Istilah konflik biasanya mengacu pada suatu kondisi di mana satu kelompok manusia (yang bisa diidentifikasi berdasarkan suku, etnis, linguistik, budaya, agama, sosioekonomi, politik, atau yang lainnya) melakukan perlawanan secara sadar terhadap satu atau beberapa kelompok lainnya karena kelompok ini dianggap mengejar tujuan-tujuan yang yang tampak tidak kompatibel".

"Kekuasaan teror Soleimani telah berakhir," ujar Trump setelah serangan pesawat nirawak AS di Nandara Baghdad, Irak, Jumat (3/1), yang merenggut nyawa komandan Pengawal Revolusi Iran tersebut. Trump berkilah rezim yang ia pimpin tidak sedang mencari perang atau hendak melakukan perubahan kepemimpinan di Iran. Sebaliknya, Trump mengaku ingin mencegah Jenderal Soleimani yang dia sebut sebagai 'monster sakit' dan 'teroris nomor satu di dunia'.

Militer Amerika Serikat melakukan serangan presisi tanpa cacat yang menewaskan teroris nomor satu di mana saja di dunia Qassem Soleimani. Soleimani merencanakan serangan yang segera dan seram terhadap para diplomat Amerika dan personel militer, tetapi kami menangkapnya dalam tindakan itu dan menghentikannya.

Pembunuhan Soleimani merupakan eskalasi dramatis dalam konflik tingkat rendah antara AS dan Iran dan yang konsekuensinya bisa sangat besar. Soleimani mempelopori operasi Timur Tengah Iran sebagai kepala Pasukan Quds. Iran berjanji akan melakukan balas dendam berat pada mereka yang menyebabkan Soleimani tewas. Rantai aksi dan pembalasan dapat terjadi membawa kedua negara lebih dekat ke konfrontasi langsung. Masa depan Washington di Irak bisa dipertanyakan. menggambarkan pembunuhan itu sebagai 'deklarasi perang' oleh AS terhadap Iran.

${ }^{30}$ Umar Suryadi Bakry, Op. Cit., hlm. 68-69. 
Kamus Besar Bahasa Indonesia W.J.S Poerwadarminta, 2006 : 194, mengemukakan bahwa:

"Membunuh artinya membuat supaya mati, menghilangkan nyawa, sedangkan pembunuhan berarti perkara membunuh, perbuatan atau hal membunuh". 31

Pasukan Quds adalah cabang pasukan keamanan Iran yang bertanggung jawab untuk operasi di luar negeri. Selama bertahun-tahun, apakah itu di Libanon, Irak, Suriah atau di tempat lain, Soleimani telah menjadi penghasut serta pembangkit utama dalam memperluas dan memperpanjang pengaruh Iran melalui perencanaan serangan atau memperkuat sekutu lokal Teheran.

Bagi Washington, dia adalah seorang pria dengan darah rakyat AS di tangannya. Tapi dia populer di Iran. Dan secara praktis, ia memimpin perlawanan Teheran terhadap kampanye tekanan dan sanksi yang dijatuhkan 'Negeri Paman Sam'. bahwa Soleimani adalah satu-satunya operasi paling kuat di Timur Tengah. Apa yang paling mengejutkan bukanlah Soleimani memang sudah berada dalam radar Presiden Trump, melainkan kenapa AS harus menyerang atau menghabisinya sekarang.

Serangkaian serangan roket tingkat rendah terhadap pangkalan AS di Irak disalahkan pada Teheran. Satu kontraktor sipil AS terbunuh. Tapi operasi Iran sebelumnya terhadap tanker di Teluk; penembakan kendaraan udara nirawak AS; bahkan serangan besar terhadap sebuah

${ }^{31}$ E Rahmanah, Op. Cit., http://www.repository.ump.ac.id [03/05/2020] fasilitas minyak Saudi semuanya berlangsung tanpa respons langsung dari AS. Dalam menjelaskan keputusan untuk membunuh Soleimani, Pentagon tidak hanya berfokus pada tindakannya di masa lalu, tetapi juga berkeras serangan itu dimaksudkan sebagai pencegah. Sang Jendral, kata pernyataan Pentagon, "Secara aktif mengembangkan rencana untuk menyerang para diplomat dan anggota layanan AS di Irak dan di seluruh kawasan."

Apa yang terjadi selanjutnya adalah pertanyaan besar. Presiden Trump setidaknya berharap dalam satu tindakan dramatis dia telah menakuti Iran dan membuktikan kepada sekutunya yang semakin tidak nyaman di kawasan seperti Israel dan Arab Saudi bahwa pencegahan AS masih memiliki taring. Pria berusia 62 tahun itu secara luas dipandang sebagai sosok paling kuat kedua di Iran, di belakang Pemimpin Tertinggi Ayatollah Ali Khamenei. Bahkan dia digadang-gadang akan menjadi pemimpin Iran berikutnya.

Soleimani bisa dibilang adalah tokoh paling kuat di republik Islam itu. Sebagai kepala militer Pasukan Quds di luar negeri, Soleimani adalah dalang di balik kegiatan 'Negeri Para Mullah' di Timur Tengah dan ibarat menteri luar negeri Iran ketika menyangkut masalah perang dan perdamaian. Dia secara luas dianggap sebagai arsitek perang Presiden Suriah Bashar al-Assad melawan pemberontak di Suriah, kebangkitan paramiliter pro-Iran di Irak, perang melawan kelompok Islamic State (IS), dan banyak pertempuran lainnya di luar negeri. Karismatik dan sering sulit dipahami, 
komandan berambut perak dihormati oleh beberapa orang, dibenci oleh yang lain, dan sumber mitos dan meme media sosial.

Pasukan Quds merupakan unit elite Korps Pengawal Revolusi Iran (IRGC), yang memberikan laporan langsung ke Ayatollah. Di bawah kepemimpinannya selama 21 tahun di Pasukan Quds, Iran mendukung Hizbullah dan kelompok-kelompok militan pro-Iran lainnya di Libanon. Kiprahnya membuat Iran memperluas kehadiran militer di Irak dan Suriah. Qassem Soleimani juga mengatur serangan Suriah terhadap kelompok-kelompok pemberontak dalam perang saudara yang panjang di negara itu.

Ketegangan Pembunuhan itu menandakan meningkatnya ketegangan antara Iran dan AS. Para pejabat AS mengatakan 3.000 tentara tambahan akan dikirim ke Timur Tengah sebagai tindakan pencegahan. Sementara itu, televisi pemerintah Irak mengatakan telah terjadi serangan udara lagi di negara itu, 24 jam setelah pembunuhan Soleimani. Namun, belum ada komentar tentang ini dari Washington. Sebuah sumber militer Irak mengatakan enam orang tewas dalam serangan baru itu yang menghantam konvoi milisi Irak pada dini hari Sabtu (waktu setempat).

\subsection{Kepentingan AS di Timur Tengah}

Mayor Jenderal Qasim Sulaimani, komandan pasukan al Quds, pasukan elit dalam Brigadir Revolusi Iran, dikabarkan meninggal oleh serangan drone nir awak AS di Irak (Kamis, 3/1/2020). Kejadian tersebut sontak memanaskan hubungan antara AS dengan Iran. Upacara pemakaman Qasim yang megah, bendera merah yang dinaikkan setiang penuh dan pernyataan Ayatullah Ali Khomenei yang menyebutkan bahwa Iran akan melakukan pembalasan dendam kepada AS. Euforia demikian mengkhawatirkan dunia. Nato dan Suriah meminta kedua belah pihak bisa menahan diri. Seolah-olah akan meletus perang terbuka antara AS dan Iran.

Ted Robbert Gurr merumuskan bahwa kekerasan politik adalah

"Sebagai bentuk dari semua tindakan kekerasan kolektif dalam suatu komunitas politik terhadap rezim politik, aktor politik, kelompokkelompok politik yang bersaing. Konsep itu menggambarkan serangkaian kejadian yang ciri pokoknya adalah penggunaan tindakan kekerasan yang termasuk dalam pengertian konsep itu adalah revolusi, perang geriliya, kudeta dan kerusuhan". 32

Sesungguhnya politik AS di Timur Tengah menggunakan 2 strategi pendekatan. Strategi pendekatan AS dilakukan berdasarkan keadaan obyektif negeri-negeri Islam di Timur Tengah. Pertama, kepada negeri-negeri Islam yang mayoritasnya Sunni. Strategi pendekatannya adalah embargo dan invasi militer. Pada tahun 1990 saat Irak menginvasi Kuwait, AS mendesak agar PBB memberikan sangsi kepada Irak. AS berambisi untuk mengamankan cadangan minyak di Kuwait sebesar 6,08 persen minyak dunia.

\footnotetext{
${ }^{32}$ Ted Robert Gurr, Op.Cit., hlm. 64.
} 
Bahkan cadangan minyak di Kuwait diprediksi baru habis dalam jangka waktu 109 tahun. 13 resolusi PBB dikeluarkan, di antaranya resolusi 661 dan 687 yang mengembargo ekonomi dan perdagangan total terhadap Irak. Dampaknya terdapat kematian sekitar 500 ribu anak karena malnutrisi dan stunting. Sedangkan di tahun 2003, AS mengumumkan akan melakukan operasi militer pembebasan Irak. Serangan besar-besaran dilancarkan guna menjungkalkan rejim Ba'ats dan membebaskan rakyat Irak dari penderitaan hidup di bawah rejim Ba'ats. Ini merupakan alibi AS untuk menyerang dan mengendalikan konstelasi politik pemerintahan di Irak.

Begitu pula invasi militer AS di Afghanistan di tahun 2001. Tragedi WTC dan Pentagon 11 september 2001 menjadi alibi AS untuk menginvasi Afghanistan. Taliban dan Al Qaeda dituding sebagai biang keladi aksi terorisme internasional. AS menghabiskan dana sekitar 750 milyar dolar untuk biaya perang dan merekonstruksi Afghanistan. Dengan demikian AS bisa mengendalikan dalam negeri Afghanistan seraya menggeser peran Rusia di sana.

Kedua, kepada negeri yang mayoritasnya syiah. Ambil contoh kepada Iran. Bagi AS, Iran itu sebagai buffer kepentingannya di Timur Tengah. Sedangkan Israel sebagai instabilisator Timur Tengah. AS berkepentingan untuk menghadang bangkitnya KeKhilafahan Islam. AS paham betul bahwa konsep keKhilafahan Islam yang diusung kaum Sunni berseberangan dengan konsep wilayatul faqihnya Syiah. Apalagi kalangan yang memperjuangkan Khilafah tidak terikat dengan satu pun negara-negara Arab. Tentunya AS harus melakukan hubungan politik dengan kolega dan antek-anteknya guna membendungnya. Maka dapat dipahami bila strategi pendekatan AS kepada negerinya kaum Sunni begitu keras. Hubungan AS dengan Iran tergolong nasdem, panas adem. Kadangkala panas, kadangkala adem. Dengan kata lain, hubungan AS dan Iran bersifat pragmatis. Qasim Sulaimani memainkan peran penting dalam hubungan AS dengan Iran. Saat invasi militer AS ke Afghanistan 2001, Qasim Sulaimani yang menghubungi perwira-perwira militer AS untuk memberitahukan kantong-kantong Taliban.

Hans Morgenthau yang sering disebut sebagai "nabi" aliran realis dalam studi Hubungan Internasional (HI) mendefinisikan power sebagai:

"Apa saja yang menciptakan dan mempertahankan pengendalian suatu negara atas negara lain, mulai dari kekerasan fisik hingga hubungan psikologis yang paling halus, misalnya melalui pengendalian pikiran". 33

Pada serangan AS ke Suriah, Qasim Sulaimani mau membantu untuk memerangi ISIS dan al Qaeda asalkan bukan untuk menyerang Basyar Assad. Qasim Sulaimani membantu AS dan hasilnya banyak berjatuhan korban dari kaum muslimin Suriah. Sempat pula terjadi ketegangan antara AS dengan Iran. Misalnya pada tanggal 3 Juli 1988. Pesawat penumpang Iran Air ditembak jatuh oleh kapal perang AS

${ }^{33}$ Umar Suryadi Bakry, Op. Cit., hlm. 65. 
Vincennes. Jumlah korban yang terhitung ada sebanyak 290 orang.

Tekanan AS terhadap Iran juga berkaitan dengan perjanjian non poliferasi nuklir di tahun 2002. AS dan Uni Eropa memberikan sangsi kepada Iran yang menyebabkan hilangnya $2 / 3$ nilai mata uangnya. Tidak ada sangsi yang demikian keras kepada Iran sebagaimana kepada Irak dan Afghanistan. Tidak ada embargo ekonomi kepada Iran.

Bahkan yang terakhir hubungan AS dan Iran bertambah panas di Irak. Qasim Sulaimani disinyalir terlibat dalam penyerangan pangkalan militer AS di Kirkuk pada 27 Desember 2019. Sebagai balasannya, AS menyerang pangkalan milisi Hizbullah di Irak dan Suriah yang menewaskan 25 orang dan 51 orang luka-luka. Dua hari kemudian, pasukan militan Syiah menyerbu Kedutaan Besar AS di Baghdad, Irak. Di dinding bangunan kedutaan AS yang hancur tertulis "Komandan Kami, Sulaimani".

AS menjawab serbuan militan Syiah tersebut dengan melancarkan serangan Drone yang menewaskan Qasim Sulaimani di Kamis 2 Januari 2020. Dalam hal ini, AS memandang bahwa Iran mencoba untuk mengambil kendali di Irak. Oleh karena itu, AS harus melakukan tindakan guna tetap memastikan Irak berada di dalam kendalinya. Sedangkan DPR Irak sendiri mengajukan protes ke PBB terkait keberadaan Irak dijadikan ajang berebut pengaruh di antara AS dan Iran yang notabenenya adalah kolega.

Iran tidak akan menantang AS untuk melakukan perang militer terbuka. Bagaimanapun juga, Iran membutuhkan dukungan dan bantuan AS untuk keberadaan pengaruh Syiahnya di Timur Tengah. Iran tidak ingin sendirian di Timur Tengah tanpa dukungan AS. Iran akan terisolir. Indonesia sendiri dalam menyikapi krisis AS Iran ini lebih memilih menahan diri. Mengingat sentimen anti Syiah di Indonesia sangatlah kuat.

Memang umat Islam mempunyai trauma terhadap keberadaan kaum Syiah. Dalam sejarah, Kaum Syiah tega mengorbankan umat Islam dengan bekerjasama dengan negaranegara imperialis. Yang penting posisinya aman. Tujuan utamanya mengambil kekuasaan Islam yang dirampas kaum Sunni.

Keruntuhan Khilafah Abbasyiah di tahun $1258 \mathrm{M}$, tidak semata-mata karena serangan Tar Tar. Seorang menteri Kholifah dari kalangan Syiah Rafidhoh, Ibnu Al qami berkhianat dengan memberitahukan kelemahan Khilafah Abbasiyah kepada Hulaghu Khan, pemimpin Tar Tar. Setelah keruntuhan Khilafah Abbasyiyah yang sunni, kepemimpinan bisa dipegang oleh Khilafah Bani Fatimiyah yang Syiah.

Begitu pula persekongkolan jahat Syiah dengan Perancis di Suriah. Sulaiman Asad, kakek dari Hafed Asad meminta perlindungan akan eksistensinya di Timur Tengah kepada Perancis. Hal ini terungkap dari dokumen perancis dengan surat bernomor 3547 pada tahun 1936. Jadi kematian Qasim Sulaimani merupakan tumbal politik dari hubungan AS dengan Iran. Sebagaimana keberadaan Qadafi dan Saddam Husain hanyalah pion politik belaka. 
Keadaan persaudaraan mereka merupakan persaudaraan antar kolega yang lebih mementingkan kepentingannya masing-masing. Harapan dan kebanggaan mereka adalah kesengsaraan kaum muslimin. Lebih-lebih mereka berkolaborasi untuk mencapai target utamanya yakni menghalangi kebangkitan dunia Islam dengan kembalinya lagi ke-Khilafahan. AS termasuk China sangatlah paham akan sepak terjang keKhilafahan dalam menghadang nafsu imperialisme mereka.

\section{Pasca Terbunuhnya Qasem Soleimani}

\subsection{Iran Menyerang Markas} Militer AS

$\begin{array}{rrr}\text { Iran } & \begin{array}{r}\text { menyerang balik } \\ \text { Amerika Serikat (AS) atas }\end{array}\end{array}$ pembunuhan Jenderal Qassem Soleimani pada Rabu (8/1/2020). Iran menembakkan serangkaian rudal balistik di dua pangkalan Irak yang menampung pasukan AS dan memperingatkan AS serta sekutunya di wilayah tersebut untuk tidak membalas. Pembalasan yang dilakukan Iran meningkatkan ketegangan di Timur Tengah. Pembalasan ini terjadi setelah Iran berbulan-bulan melakukan ancaman usai keputusan Presiden AS Donald Trump untuk menarik Amerika secara sepihak dari perjanjian nuklir Teheran.

Serangan itu sebagai pembalasan atas pembunuhan Qassem Soleimani yang dilakukan AS. Prosesi pemakaman Soleimani pada Selasa (7/1/2020) di kota kelahirannya di Kerman memicu seruan untuk membalas kematiannya. Pembunuhan Soleimani dan serangan rudal Iran juga menandai pertama kalinya dalam beberapa tahun terakhir Washington dan Teheran saling menyerang secara langsung daripada melalui proksi di wilayah tersebut. Ini meningkatkan kemungkinan konflik terbuka meletus antara kedua negara, yang telah menjadi musuh sejak Revolusi Islam Iran pada 1979.

Garda Revolusi Iran memperingatkan AS dan sekutu agar tidak membalas serangan rudal di pangkalan udara Ain al-Asad, Provinsi Anbar barat Irak. Garda mengeluarkan peringatan melalui pernyataan yang dibawa oleh kantor berita IRNA milik pemerintah Iran. "Kami memperingatkan semua sekutu Amerika, yang memberikan pangkalan kepada tentara teroris, bahwa setiap wilayah yang merupakan titik awal dari tindakan agresif untuk membalas Iran akan menjadi sasaran," kata Garda.

Ancaman ini juga ditujukan untuk Israel. Setelah serangan itu, seorang mantan negosiator nuklir Iran memposting gambar bendera Republik Islam di Twitter. Twit ini muncul untuk meniru Trump yang memasang bendera Amerika setelah pembunuhan Soleimani pada Jumat dalam serangan pesawat tanpa awak di Baghdad. Pangkalan udara Ain alAsad pertama kali digunakan oleh pasukan AS setelah invasi AS tahun 2003 yang menggulingkan Saddam Hussein. Pasukan AS kemudian ditempatkan di sana di tengah perang melawan ISIS di Irak dan Suriah. Pangkalan ini menampung sekitar 1.500 pasukan AS dan koalisi.

Serangan balas dendam pada Rabu datang hanya beberapa jam setelah para pelayat di Iran berduka atas kematian Soleimani. Serangan 
datang ketika AS terus memperkuat posisinya di wilayah tersebut, setelah muncul ancaman serangan kapal pengiriman dari Iran di wilayah air, rute penting pengiriman pasokan energi global. Kedutaan dan konsulat AS dari Asia ke Afrika dan Eropa mengeluarkan peringatan keamanan untuk Amerika. Angkatan Udara AS meluncurkan latihan dengan 52 jet tempur di Utah, hanya beberapa hari setelah Trump mengancam akan menyerang 52 lokasi di Iran.

\subsection{AS Mendapat Kecaman dari Dunia Internasional}

Terbunuhnya perwira tinggi Angkatan Bersenjata Iran, Mayor Jenderal Qasem Soleimani pada Jumat (3/1), dalam serangan udara AS di Bandara Internasional Baghdad, Irak direspons sejumlah negara. Banyak yang khawatir tindakan AS tersebut akan memprovokasi Iran dan memicu terjadinya Perang Dunia III. Adapun serangan AS terhadap Soleimani ini juga membuat beberapa negara di dunia turut buka suara.

Presiden Rusia Vladimir Putin menyuarakan keprihatinan atas kejadian tersebut. Demikian pula Presiden Prancis, Emmanuel Macron, ikut merespons serangan udara AS yang menewaskan seorang komandan tinggi Iran. Kedua pemimpin dunia itu mengemukakan kemungkinan pembunuhan Jenderal Qasem Soleimani dapat meningkatkan situasi yang lebih panas di Timur Tengah. Di waktu berbeda, Kementerian Pertahanan Rusia mengatakan dalam sebuah pernyataan bahwa pemogokan itu akan mengarah pada peningkatan tajam di kawasan itu, dan memuji Soleimani sebagai seorang pemimpin militer yang kompeten, memiliki otoritas yang layak dan pengaruh besar di seluruh kawasan Timur Tengah.

Sementara itu, Pakistan dan India juga mendesak untuk menahan diri setelah pembunuhan Soleimani. Pakistan menyatakan keprihatinan mendalam atas kejadian pembunuhan komandan elit Iran Quds Force Qasem Soleimani dalam serangan pesawat tak berawak AS di Irak. Kementerian Luar Negeri Pakistan mengatakan eskalasi di Timur Tengah sangat mengancam perdamaian dan stabilitas di kawasan itu. Pakistan juga meminta semua pihak yang berkepentingan untuk menahan diri secara maksimal atau terlibat secara konstruktif untuk mengurangi situasi panas. Penghormatan terhadap kedaulatan dan integritas teritorial adalah prinsip dasar Piagam PBB, yang harus dipatuhi. Penting juga untuk menghindari tindakan sepihak dan penggunaan kekuatan. Sementara itu Kementerian Urusan Luar Negeri India mengatakan New Delhi telah secara konsisten menganjurkan pengendalian diri dan terus melakukannya. "Kami telah mencatat bahwa seorang pemimpin senior Iran telah terbunuh oleh AS. Meningkatnya ketegangan telah mengejutkan dunia. Perdamaian, stabilitas dan keamanan di kawasan ini sangat penting bagi India.

Sangat penting bahwa situasi tidak meningkat lebih jauh. Tidak hanya itu, pemerintah Afrika Selatan pun mengatakan pihaknya khawatir dengan meningkatnya ketegangan di Irak yang bisa berdampak jauh tidak hanya bagi 
Timur Tengah, tetapi juga perdamaian dan keamanan internasional.

Afrika Selatan menegaskan kembali dukungan Dewan Keamanan PBB untuk kemerdekaan, kedaulatan, persatuan, integritas teritorial dan kemakmuran Irak," kata Departemen Hubungan Internasional dan Kerjasama dalam sebuah pernyataan. Pernyataan itu dikeluarkan beberapa jam setelah AS mengkonfirmasi pembunuhan Jenderal Qasem Soleimani yang merupakan pemimpin dari Quds Force selaku satuan pasukan khusus yang dimiliki Revolutionary Guards (salah satu bagian dari pasukan bersenjata Iran) dan Abu Mahdi al-Muhandis yang merupakan wakil komandan dari Popular Mobilization Forces selaku kelompok milisi Irak yang dibekingi oleh Irandalam sebuah serangan udara. Demikian pula Pemerintah Indonesia ikut angkat bicara mengenai meningginya tensi geopolitik antara Amerika Serikat (AS) dan Iran. Kedua belah pihak, diminta untuk menahan diri.

\subsection{Keuntungan Amerika Serikat dan Iran}

Ada beberapa hal yang menarik dari konflik antara Iran dan Amerika Serikat. Yang pertama adalah tentang legalitas serangan Amerika terhadap Qassem Soleimani. serangan Amerika tersebut adalah pelanggaran hukum. Ini lantaran serangan diluncurkan tidak pada saat terjadi peperangan. Yang menarik dari konflik tegangan eskalasi yang meningkat antara Amerika dan Iran ada tiga hal, diantaranya:
Pertama mengenai legalitas serangan itu sendiri ketika Amerika membunuh seorang Komandan atau panglima negara lain yang tidak bersenjata bukan dalam keadaan perang itu wajar kalau Iran marah, jadi ada pelanggaran hukum disini. Hal kedua adalah adanya pihak yang diuntungkan dari meninggalnya Qassem Soleimani. Pihak pertama yang diuntungkan adalah Iran, yang kedua yang menarik dari kematian solemani adalah siapa yang diuntungkan?

Yang pertama ini keuntungan dalam arti bisa sengaja atau tidak sengaja, yang pertama Iran tentu saja diuntungkan, Ini lantaran dengan meninggalnya Qassem Soleimani rakyat Iran kembali bersatu.

Bulan lalu sempat ada ramai demonstrasi anti pemerintah di Iran, media barat menggambarkan rakyat Iran sudah tidak suka dengan rezim yang sekarang. Setelah Soleimani tewas ratusan ribu hingga jutaan orang yang menghadiri pemakamannya itu membuktikan rakyat Iran bersatu untu mendiang Soleimani. Pihak lain yang diuntungkan adalah Donald Trump.

Yang ketiga siapa lagi yang diuntungan selain iran tentu saja Trump. Trump kan saat ini popularitasnya turun, sedangkan Amerika selama ini selalu menganggap Iran musuh bebuyutan Amerika.

Meninggalnya Qassem Soleimani mampu meningkatkan popularitas Trump yang saat ini tengah turun.

Menurut Charles Beard menyatakan bahwa:"Kepentingan nasional adalah alasan negara (raison d'etat) di belakang tujuan-tujuan dan ambisi- 
ambisinya menjalankan hubungan internasional". ${ }^{34}$

Jadi dengan terbunuhnya solemani yang merupakan simbol Iran itu popularitas Trump otomatis naik. Pihak terakhir yang diuntungkan adalah Arab Saudi dan Israel. Selain itu yang diuntungkan adalah Arab Saudi dengan Israel, hubungan ketiga negara antara arab Saudi, Israel dan Amerika semakin kuat karena mereka menggap Iran sebagai musuh. kehilangan seorang jenderal dalam sebuah peperangan adalah sebuah konsekuensi. Perang tersebut bisa terjadi ketika salah satu negara yang kehilangan jenderal memiliki niatan untuk melakukan aksi balas dendam.

Negara yang kehilangan jenderal itu mempunyai ambisi membalas itulah perang. Saat ini Amerika harus memperhitungkan langkah apa yang akan diambil untuk nantinya menghadapi balasan Iran. Tak hanya itu Amerika juga dihimbau untuk memperhitungkan konsekuensi yang akan didapatkannya karena telah membunuh jenderal Iran.

Kehilangan seorang prajurit harus dibalas prajurit musuh, makin tinggi misalnya satu letnan harus sepuluh orang satu mayor 15 orang seorang jenderal harus berapa? Itu konsekuensi yang harus diperhitungkan Amerika. Seperti diketahui aksi ini merupakan dampak dari serangan rudal Amerika Serikat yang menewaskan Komandan Pasukan Quds, Qasem Soleimani dan Kepala Hashed, Abu Mahdi alMuhandis di Bandara Internasional Baghdad, Irak, Jumat (3/1/2020). Akibat hal ini Iran lantas melakukan

${ }^{34}$ Umar Suryadi Bakry, Op. Cit., hlm. 58. serangan balasan ke pangkalan militer AS di Ain Al Asad Provinsi Anbar Irak menggunakan rudal jelajah.

Serangan dilakukan langsung pasukan artileri Korps Garda Republik Iran. Namun aksi ini bukanlah pemicu serangan balas dendam yang akan dilakukan oleh Iran. bahwa Iran akan membuat kalkulasi yang sangat kuat untuk melancarkan aksi balas dendamnya. Ini tidak serta merta dilakukan Iran sebagai pemicu serangan balas dendam yang sangat masif, Iran akan melakukan kalkulasi yang sangat kuat. bahwa serangan rudal ini bukanlah serangan kuat yang dilakukan Iran.

Akan ada serangan yang lebih membahayakan lagi yang dapat membuat Amerika kedodoran. Yaitu serangan cyber .Karena itu mungkin rudal ini hanya permukaan saja tapi yang bergerak yang paling lebih berbahaya yang paling ditakutkan adalah serangan cyber. Serangan cyber ini dinilai sebagai kekuatan yang dimiliki oleh Iran. Karena kekuatan pasukan luar Iran itu adalah di cyber, Amerika sempat kedodoran, sehingga mesti meratifikasi penjagaan nuklirnya dengan Iran.

\section{Kesimpulan}

Amerika Serikat memiliki sejarah keterlibatan yang panjang di kawasan Timur Tengah karena eksistensi Israel sabagai sekutu dekatnya. Bukanlah rahasia umum bahwa Amerika adalah musuh dari sebagian besar negara Timur Tengah. Di sisi lain, Iran merupakan salah satu seteru AS yang secara agresif terus mengembangkan kekuatannya, sehingga AS akan berusaha 
melemahkan dan menghambat perkembangan Iran. Pembunuhan Soleimani dapat diinterpretasikan sebagai salah satu bentuk dari upaya tersebut, dengan justifikasi bahwa Soleimani memiliki niatan untuk menyerang beberapa target strategis di Amerika. Namun pada kenyataannya, justifikasi yang disebutkan oleh pihak Gedung Putih tersebut masih belum bisa dibuktikan keabsahannya. Sebaliknya, muncul pandangan yang menyatakan bahwa Donald Trump melakukan serangan tersebut adalah sebuah pengalihan isu untuk mengurangi beban dalam negeri AS yang sedang marak dengan isu pemakzulan Trump, sekaligus sebagai upaya mendongkrak popularitas Trump pada pemilu yang akan datang. Siasat ini pernah diterapkan oleh mantan Presiden AS, George H. Bush Sr. yang mengintervensi dalam invansi Irak ke Kuwait. Namun siasat ini dapat berbalik merugikan Trump apabila lawan politik Trump menggunakan isu ekonomi sebagai pertimbangan dalam inisiasi perang, dimana kondisi perekonomian AS sebenarnya tidak cukup kuat untuk mendukung ekonomi perang apabila AS berperang dengan Iran.

Meskipun kehilangan seorang pemimpin militer yang berpengaruh, kematian Qasem Soleimani dapat menguntungkan Iran untuk jangka pendek. Kematian sang jenderal, dan prosesi pemakaman yang begitu massif, memungkinkan Teheran mengalihkan perhatian publik dari penumpasan terhadap protes-protes sehubungan dengan kenaikan harga minyak pada November 2019.

Iran mempunyai kesempatan menunjukkan kemampuan bersatu pada saat krisis, mempersatukan elite politik yang selama ini terpecah belah. Iran mengalami tekanan ekonomi akibat dari sanksi-sanksi AS terbaru setelah Presiden Trump menarik negara itu dari perjanjian nuklir Iran tahun 2018. Tahun lalu, terjadi eskalasi setelah Iran menembak jatuh drone AS dan menahan kapal-kapal pengangkut kargo.

Iran telah membalas serangan AS dengan rudal. Sasarannya adalah pasukan AS di Irak. Iran mungkin saja diuntungkan jika mengulur-ulur waktu pembalasan lanjutan dan sebaliknya terus memainkan simpati publik dan keresahan tentang apa yang akan terjadi. Kendati demikian, jika Iran mengambil tindakan lagi dianggap sebagai pihak yang menang.

Pemerintah AS di bawah Presiden Donald Trump mungkin saja telah berhasil melukai kekuatan militer Iran. Pada saat bersamaan, peristiwa ini bisa jadi meningkatkan peluang Trump untuk dipiih lagi dalam pemilihan presiden November mendatang. Krisis ini juga telah memberikan pesan solidaritas dan kekuatan kepada sekutu-sekutunya Israel dan Arab Saudi. Namun jika situasi ini terseret ke aksi saling balas maka hal itu dapat mendongkrak harga minyak, menyebabkan kematian lebih banyak di pihak AS, dan memicu perang regional jangka panjang. Hal tersebut berpotensi menimbulkan dampak bagi banyak negara di Timur Tengah dan kawasan-kawasan lain.

Konflik ini mengubah secara drastis the level of the game dalam hubungan antara Amerika Serikat dan Iran termasuk dengan sekutu- 
sekutunya masing-masing. Iran memang melakukan pembalasan ofensif yang akan mempersempit ruang dialog. Apalagi parlemen Iran telah secara resmi memutuskan bahwa pembunuhan Qasem Soleimani merupakan tindakan terorisme.

Bahwa eskalasi konflik Iran dan Amerika yang meningkat akan berdampak pada konflik terbuka yang makin meluas. Namun demikian, kemungkinan terjadinya Perang Dunia Ketiga Sebagaimana dikhawatirkan berbagai pihak membutuhkan perkembangan situasi lain. Negara-negara dunia telah mengambil pelajaran bagaimana besarnya kerusakan pasca Perang Dunia Pertama dan Kedua. Dengan keberadaan senjata nuklir dewasa ini, Perang Dunia III dapat dipastikan merupakan Perang Nuklir. Itu berarti akhir dari dunia (the end of the world). Hal itu akan dihindari oleh berbagai pemimpin rasional, termasuk di Iran dan Amerika Serikat.

\section{Daftar Pustaka}

Heywood Andrew, Politik Edisi Keempat, Yogyakarta: Pustaka Pelajar, 2014.

Budi Winarno, Dinamika Isu-Isu Global Kontemporer, Yogyakarta: CAPS (Center of Academic Publishing Service), 2014.

Didi Krisna, Kamus Politik Internasional, Jakarta: PT Gramedia Widiarsana, 1993.

Tom Finaldin, Pengantar Penyusunan Karya Ilmiah (Untuk Lingkungan Sendiri),
Bandung: Fakultas Ilmu Sosial dan Ilmu Politik Universitas Al-Ghifari, 2017.

Ibnu Burdah, Konflik Timur Tengah Aktor, Isu, dan Dimensi Konflik, Yogyakarta: Tiara Wacana, 2008.

Robert Jackson, Georg Sorensen, Pengantar Studi Hubungan Internasional Teori dan Pendekatan Edisi Kelima, Yogyakarta: Pustaka Pelajar, 2016.

Scott Burchill, Andrew Linklater, Teori-Teori Hubungan Internasional, Bandung: Nusa Media, 1996

Sugiyono, Metode Penelitian, Kuantitatif, Kualitatif dan $R \& D$, Bandung: CV Alfabeta, 2018.

Umar Suryadi Bakry, Dasar-Dasar Hubungan Internasional, Jakarta: Prenadamedia Group, 2017.

Umar Suyadi Bakry, Pedoman Penulisan Skripsi Hubungan Internasional, Yogyakarta: Deepublish Publisher, 2016.

Yanuar Ikbar, Metodologi \& Teori Hubungan Internasional, Bandung: PT Refika Aditama, 2014.

\section{Internet:}

CNN Indonesia, "Konflik AS-Iran, Ancaman Petaka dari Timur Tengah" 09 (Januari) 2020 , http://m.cnnindonesia.com/internasio nal/20200109104223-120463756/konflik-as-iran-ancaman- 
petaka-dari-timur-tengah

[02/02/2020]

Ahmad Naufal Dzulfaroh, "Merunut Akar Konflik Iran-Amerika Serikat, Sejak Kapan Perseturuan Dimulai?" $10 \quad$ (Januari) 2020, http://www.kompas.com/tren/read/20 20/01/10/103042265/merunut-akarkonflik-iran-amerika-serikat-sejakkapan-perseteruan-dimuai [02/02/2020]

Haufan Hasyim Salengke, "Kenapa AS Akhirnya Membunuh Jenderal Top Iran Qaseem Soleimani?" 049 (Januari) 2020, https://mediaindonesia.com/read/deta il/281289-kenapa-as-akhirnyamembunuh-jenderal-top-iranqaseem-soleimani [20/02/2020]

Benedikta Miranti Tri Verdiana "Kepada PBB, AS Sebut Pembunuhan Qasem Soleimani Jadi Cara Untuk Bela Diri" 09 (Januari) 2020,

https://m.liputan6.com/global $/ \mathrm{read} / 4$ 151867/kepada-pbb-as-sebutpembunuhan-qasem-soleimani-jadicara-untuk-bela-diri [20/02/2020]

Neno Anderias Salukh, "Mengapa AS Membunuh Jenderal Top Iran (Qassem Soleimani)? 04 (Januari) 2020 , https://www.kompasiana.com/neno1 069/5e10204a097f360cac3a83b2/me ngapa-as-membunuh-jenderal-topiran-qassem-soleimani [20/02/2020]

Ahmad Naufal Dzulfaroh, "Merunut Akar Konflik Iran-Amerika Serikat, Sejak Kapan Perseteruan Dimulai" 10 (Januari) 2020, https://www.kompas.com/tren/read/2 $\underline{\text { 020/01/10/103042265/merunut-akar- }}$ konflik-iran-amerika-serikat-sejakkapan-perseteruan-dimulai [06/03/2020]

E Rahmanah, "Pembunuhan Berencana (Tinjauan Yuridis Terhadap Putusan Pengadilan Tinggi Nomor: 15/PID/2012/PT.BTN) 2016, http://www.repository.ump.ac.id [03/05/2020]

E Rahmanah, "Pembunuhan Berencana (Tinjauan Yuridis Terhadap Putusan Pengadilan Tinggi Nomor: 15/PID/2012/PT.BTN) 2016, http://www.repository.ump.ac.id [03/05/2020]

Ani Nursalikah, "Mengenal Garda Revolusi Islam yang Disebut Trump Teroris", 2020, http://www.republika.co.id [13/05/2020]

Redaksi WE Online "Siapa Jenderal Qassem Soleimani, yang Terbunuh dalam Serangan Udara AS?", 2020, http://www.wartaekonomi.co.id [13/05/202]

Wikipedia, "Amerika Serikat" (Tanpa Tahun), https://www.wikipedia.org [19/06/2020]

Wikipedia, "Iran" (Tanpa Tahun), https://www.wikipedia.org [19/06/2020] 